\title{
Pairwise coupling analysis of helical junction hydrogen bonding interactions in luteoviral RNA pseudoknots ${ }^{\dagger}$
}

\author{
Peter V. Cornish ${ }^{1}$ and David P. Giedroc ${ }^{*}$ \\ Department of Biochemistry and Biophysics, 2128 TAMU, Texas A\&M University, College Station, \\ TX 77843-2128
}

\section{Abstract}

A 28-nucleotide mRNA pseudoknot that overlaps the P1 and P2 genes of sugarcane yellow leaf virus (ScYLV) stimulates -1 ribosomal frameshifting. The in vitro frameshifting efficiency is decreased $\approx 8$ fold upon substitution of the $3^{\prime}$ most loop 2 nucleotide (C27) to adenosine, which accepts a hydrogen bond from the 2'-OH of C14 in stem S1. The solution structures of the wild-type (WT) and the C27A ScYLV RNA pseudoknots show that while the RNAs adopt virtually identical overall structures, there are significant structural differences at the helical junctions of the two RNAs. Specifically, $\mathrm{C}^{+}$in loop $\mathrm{L} 1$ in the $\mathrm{C}^{+} \cdot(\mathrm{G} 12-\mathrm{C} 28) \mathrm{L} 1-\mathrm{S} 2$ major groove base triple is displaced by $\approx 2.3$ A relative to the accepting stem 2 base pair (G12-C28) in the C27A RNA. Here, we employ a double mutant cycle approach to analyze the pairwise coupling of the $\mathrm{C} 8^{+} \cdot(\mathrm{G} 12-\mathrm{C} 28)$ and $\mathrm{C} 27 \cdot(\mathrm{C} 14-$ G7) or A27.(C14-G7) hydrogen bonds in the WT and C27A ScYLV RNAs, respectively, and compare these findings with previous results from the beet western yellows virus (BWYV) RNA. We find that the pairwise coupling free energy $\left(\delta_{\mathrm{AB}}{ }^{i}\right)$ is favorable for the WT RNA $(-0.7 \pm 0.1$ $\mathrm{kcal} \cdot \mathrm{mol}^{-1}$ ), thus revealing that formation of these two hydrogen bonds is positively cooperative. In contrast, $\delta_{\mathrm{AB}}{ }^{i}$ is $+0.9 \pm 0.4 \mathrm{kcal} \cdot \mathrm{mol}^{-1}$ for the poorly functional C27A ScYLV RNA, indicative of non-additive hydrogen bond formation. These results reveal that cooperative hydrogen bond formation across the helical stem junction in H-type pseudoknots correlates with enhanced frameshift stimulation by luteoviral mRNA pseudoknots.

\section{Keywords}

pseudoknot; frameshifting; protonated cytidine; hydrogen bond coupling

\begin{abstract}
Intricately folded motifs in both the noncoding and coding regions of mRNAs are known to regulate all steps of the translation cycle. RNA functions in cap-independent translational initiation by providing a binding site for $40 \mathrm{~S}$ ribosomal subunits in internal ribosomal entry sites (IRES) (1). Riboswitches are naturally occurring aptamers that bind metabolites including adenine, guanine, $S$-adenosylmethionine, and thiamine pyrophosphatase that directly regulate the expression of enzymes linked to their production or degradation (2). Folded RNA motifs found in coding regions of mRNAs regulate ribosomal recoding by stimulating stop codon suppression, stop codon redefinition, or change the translational reading frame, an example of which is -1 programmed ribosomal frameshifting $(-1$ PRF) $(3,4)$. -1 PRF occurs during translational elongation where the mRNA slips back by one nucleotide into the " -1 " reading frame relative to the reference " 0 " frame. In RNA viruses, -1 PRF is used to produce several
\end{abstract}

\footnotetext{
${ }^{\dagger}$ This work was supported by grants from the NIH (AI040187) and the Texas Higher Education Coordinating Board Advanced Research Program (010366-0172-2001). P. V. C. was supported in part by an NIH Chemistry-Biology Interface Training Grant (T32 GM08523).

*To whom correspondence should be addressed: Phone: 979-845-4231; Fax: 979-845-4946; Email: giedroc@ tamu.edu.

${ }^{1}$ Current address: Department of Physics, University of Illinois at Urbana-Champaign, 1110 West Green Street, Urbana, IL 61801-3180.
} 
proteins $(\mathrm{P} 1, \mathrm{P} 2)$ from a single ribosomal initiation site while regulating the relative ratios of gene products (P1 vs. P1-P2) as dictated by the efficiency of the frameshift. Maintaining a proper ratio of gene products has been shown to be important for viral propagation and infectivity in retroviruses and yeast retrotransposable elements (5-9).

For efficient frameshifting to occur, several elements must be present in the mRNA (10). The first is a slip site, which in most cases conforms to the sequence X XXY YYZ, where $\mathrm{X}$ is any nucleotide, $\mathrm{Y}$ is $\mathrm{A}$ or $\mathrm{U}$, and $\mathrm{Z}$ is any nucleotide except $\mathrm{G}$ (11). The slip site is positioned in the $\mathrm{A}$ and $\mathrm{P}$ sites of the ribosome at the time frameshifting occurs. Also required for efficient frameshifting is an RNA structural element, which in many cases is an RNA pseudoknot. This RNA structural element is separated from the $3^{\prime}$ edge of the slip site by a 6 to 8 nucleotide linker. The linker length is likely required for optimally positioning the pseudoknot at the mRNA entry tunnel of the ribosome where the RNA helicase activity is thought to be localized (12-14).

$-1 \mathrm{PRF}$ is responsible for the production of the genomically encoded P1 and P1-P2 fusion proteins in plant luteoviruses (15). The stimulatory RNA structure in luteoviral mRNAs is a hairpin (H)-type RNA pseudoknot, which contains two helical stems (S1, S2) connected by nonequivalent loops (L1, L2). Luteoviral RNA pseudoknots are characterized by an intricate collection of stabilizing tertiary structural loop-loop and loop-stem hydrogen bonding interactions (16-19). A C $\mathrm{C}^{+}$.(G-C) L1-S2 major groove trans Watson-Crick/Hoogsteen base triple has been observed in all luteoviral pseudoknots thus far investigated and protonation has been shown to be stabilizing by $2-3 \mathrm{kcal} \cdot \mathrm{mol}^{-1}$ at $37^{\circ} \mathrm{C}(20)$. Further, this interaction is essential for the efficient frameshift stimulation by these pseudoknots $(16,17,21,22)$. Two L2$\mathrm{S} 1$ minor groove interactions at the helical junction have also been shown to be important for pseudoknot stability and maintenance of frameshifting efficiency (20).

The solution structure of the P1-P2 frameshifting mRNA pseudoknot from sugarcane yellow leaf virus ( $\mathrm{ScYLV}$ ) is unique since the $\mathrm{L} 2-\mathrm{S} 1$ minor groove base triple closest to the helical junction is formed by an L2 cytidine (C27) rather than an adenosine, which is found in this position in all other luteoviral RNAs (16) (see Fig. 1A,B). Surprisingly, substitution of C27 with adenosine resulted in a nearly complete abrogation of ScYLV pseudoknot-stimulated frameshifting in a simple in vitro assay (from $15 \%$ to $1.8 \%$, or $\approx 2$-fold above slip-site alone), with virtually no change in the global structure of the RNA $(16,23)$. The major structural difference was found at the helical junction (23). Formation of the C27.(C14-G7) minor groove triple in the WT ScYLV pseudoknot at the helical junction (Fig. 1B) allows for the rearrangement of the immediately adjacent major groove $\mathrm{C} 8^{+} .(\mathrm{G}-\mathrm{C})$ base triple on which it is stacked, so that $\mathrm{C} 8$ moves $\approx 2.3 \AA$ relative to the accepting base pair (G12-C28) when compared to the C27A ScYLV RNA (23) (Fig. 1C). This rearrangement likely contributes to a global destabilization of the $\mathrm{C} 27 \mathrm{~A}$ RNA by $\approx 1-1.5 \mathrm{kcal} \cdot \mathrm{mol}^{-1}\left(\Delta \Delta G_{37}\right)$ relative to the WT RNA (16).

The relationship between global stability and frameshift stimulation is not entirely clear. The global stability of the downstream structural element, per se, cannot be fully responsible for frameshifting since an RNA hairpin of a global stability similar to that of an RNA pseudoknot does not induce comparable levels of frameshift stimulation $(24,25)$. This suggests that there is some feature encoded in the pseudoknot topology itself that is capable of modulating frameshift stimulation. Since structure is unlikely to play a major role (23), one possibility is that a small localized destabilization of the helical junction itself is a major contributor to a decrease in global stability and this, in turn, might account for functional differences between structurally similar RNA pseudoknots. We reasoned that such a destabilization in the C27A ScYLV RNA relative to the WT RNA may well originate with distinct energies of pairwise coupling, $\delta_{\mathrm{AB}}{ }^{i}$, of the two stacked hydrogen bonds that cross the helical junction in these two 
RNAs $(16,23)$ (see Fig. 1). In this paper, we employ thermal melting experiments carried out as a function of $\mathrm{pH}$ with site-specific deoxycytidine (dC)-substituted RNAs to elucidate $\delta_{\mathrm{AB}}{ }^{i}$ of the $\mathrm{C}^{+} \mathrm{H} 3-\mathrm{G} 12 \mathrm{O} 6$ and $\mathrm{C} 27 \mathrm{~N} 3-\mathrm{C} 142^{\prime}-\mathrm{OH}\left(\delta_{\mathrm{AB}}{ }^{\mathrm{WT}}\right)$ or A27 N1-C14 2'-OH $\left(\delta_{\mathrm{AB}}{ }^{\mathrm{C} 27 \mathrm{~A}}\right)$ hydrogen bonding interactions at the helical junction of the WT vs. C27A ScYLV RNAs and compare these findings to previous studies of the related frameshifting mRNA from beet western yellows virus (BWYV) (see Fig. 1D) (20). We find that both WT RNAs are characterized by a $\delta_{\mathrm{AB}}{ }^{i}$ consistent with cooperative hydrogen bond formation. In contrast, the C27A ScYLV RNA is characterized by a pairwise coupling indicative of non-additive hydrogen bond formation, despite the fact the helical junction regions of the weakly functional C27A ScYLV and wild-type BWYV RNAs are quite similar (23). The implications of these findings on pseudoknot-mediated frameshift stimulation are discussed.

\section{Materials and Methods}

\section{RNA synthesis and sample preparation}

The WT and C27A ScYLV RNAs were synthesized by in vitro transcription using SP6 RNA Polymerase as described previously (16). The dC14 and dC14/C27A ScYLV RNAs were purchased from Dharmacon (Boulder, $\mathrm{CO}$ ) and deprotected according to the manufacturers recommendations. All four RNAs were purified by denaturing PAGE, electroeluted, and desalted using $\mathrm{C} 18$ chromatography. The RNA samples were prepared for melting experiments by extensive dialysis (over $\approx 9 \mathrm{~h}$ ) against several changes of buffer for a total of $2 \mathrm{~L}$ of the appropriate buffer containing $0.5 \mathrm{M} \mathrm{KCl}$. The first buffer change contained $5 \mathrm{mM}$ EDTA to remove adventitiously bound divalent metal ions. The following buffers were used at a final concentration of $10 \mathrm{mM}$ : acetate (pH 5.0), MES (pH 5.5 and $\mathrm{pH} 6.0$ ), MOPS (pH 6.5 and $\mathrm{pH}$ 7.0), EPPS (pH 7.5, $\mathrm{pH} 8.0$, and $\mathrm{pH} 8.5$ ), and CHES (pH 9.0) (26).

\section{NMR sample preparation and spectroscopy}

All samples were prepared for NMR spectroscopy by multiple rounds of ethanol precipitation. The final NMR buffer was $10 \mathrm{mM}$ potassium phosphate, $100 \mathrm{mM} \mathrm{KCl}$ and $5 \mathrm{mM} \mathrm{MgCl}_{2}, \mathrm{pH}$ 6.0 , with a final sample concentration of $\sim 2 \mathrm{mM}$ for WT ScYLV, $\sim 1 \mathrm{mM}$ for C27A ScYLV, and $\sim 0.5 \mathrm{mM}$ for $\mathrm{dC} 14$ and dC14/C27A ScYLV RNAs. The proton resonances were referenced to an internal standard (100 $\mu \mathrm{M}$ DSS). The jump-return echo 1D spectra were recorded at a proton resonance frequency of $500 \mathrm{MHz}$. For each spectrum, 512 transients were collected with a spectral width of $12.5 \mathrm{kHz}$ and 2048 complex points. Watergate ${ }^{1} \mathrm{H}-{ }^{1} \mathrm{H}$ NOESY spectra $\left(\tau_{\mathrm{mix}}=200 \mathrm{~ms}\right)$ were collected with 1024 complex points in the direct dimension and 512 complex points in the indirect dimension with spectral width of $12.5 \mathrm{kHz}$ in each dimension in order to obtain imino proton and 2'-OH proton resonance assignments.

\section{Optically-detected melting experiments and data analysis}

Optical melting experiments were performed on a Cary 1 spectrophotometer equipped with a temperature controller. The temperature range was increased from 5 to $95^{\circ} \mathrm{C}$ at a constant ramp rate of $0.3{ }^{\circ} \mathrm{C} / \mathrm{min}$. Absorbance data were acquired at 260 and $280 \mathrm{~nm}$ and both sets of derivative data $\left(\mathrm{dA}_{260} / \mathrm{dT}\right.$ and $\left.\mathrm{dA}_{280} / \mathrm{dT}\right)$ were subjected to a simultaneous nonlinear least squares fit to a multiple $(i)$ sequential interacting two-state transition model that optimizes $\Delta H_{\mathrm{i}}$ and $t_{\mathrm{m}, \mathrm{i}}$ for the unfolding of each $i$ th unfolding step as implemented by the algorithm tmelt assuming $\Delta C_{\mathrm{p}}{ }^{\mathrm{o}}=0(27,28)$. The criteria used to determine the number of unfolding transitions is described in the text and elsewhere (16). The final RNA concentration for the UV melting experiments was $2 \mu \mathrm{M}$ in a $600 \mu \mathrm{L}$ cuvette. Three or more useable melting profiles were collected for each solution condition and analyzed individually to extract $\Delta H_{\mathrm{i}}$ and $t_{\mathrm{m}, \mathrm{i}}$ with the resulting parameters obtained from multiple experiments averaged (see Tables S1-S4, Supporting Information). The unfolding entropies were obtained from $\Delta S_{i}=\Delta H_{i} / t_{\mathrm{m}}$ while $\Delta G_{37}=\Delta H_{\mathrm{i}}-310.15^{*} \Delta S_{\mathrm{i}}$. Folding parameters assume microscopic reversibility where 
$\Delta G_{37}$ (unfolding) $=-\Delta G_{37}$ (folding) and $\Delta H_{\mathrm{vH}}$ (unfolding) $=-\Delta H_{\mathrm{vH}}$ (folding). Here, we report $\Delta G_{37}$ (folding). Melting experiments performed at higher and lower RNA concentrations were used to establish unimolecular unfolding behavior of all RNAs studied here. Additionally, extensive NMR investigation of the WT and C27A RNAs at concentrations as high as $3 \mathrm{mM}$ showed no signs of aggregation (data not shown) (16).

\section{Results \\ Imino ${ }^{1} \mathrm{H}$ NMR spectroscopy}

It was first important to establish the degree to which the $\mathrm{dC} 14$ substitution influences the structure of the WT and C27A ScYLV RNAs. The downfield regions of jump-return echo 1D NMR spectra acquired at $10{ }^{\circ} \mathrm{C}, \mathrm{pH} 6.0$ for each of the four RNAs are shown in Fig. 2. The resonance assignments shown for $\mathrm{dC} 14$ and dC14/C27A ScYLV RNAs were confirmed by a $200 \mathrm{~ms}$ Watergate ${ }^{1} \mathrm{H}-{ }^{1} \mathrm{H}$ NOESY spectrum collected at $10^{\circ} \mathrm{C}$ (data not shown). The $1 \mathrm{D}$ spectra of the WT and dC14 ScYLV RNAs clearly show that both RNAs are stably folded and that the $\mathrm{C} 8^{+}$imino and amino protons are present; both features are diagnostic for the trans WatsonCrick/Hoogsteen C+·(G-C) interaction between C8+ and the G12-C28 base pair (29) (see Fig. $1 \mathrm{~B}, \mathrm{C})$. Although the imino proton chemical shift of $\mathrm{C} 8+$ is degenerate with that of $\mathrm{G} 30$ in the C27A RNA and G6 in the dC14/C27A RNA, both RNAs are stably folded since the amino protons are clearly present (Fig. 1C,D). As expected, the 2'-OH of C14 is absent in the dC14/ C27A ScYLV RNA (Fig. 2D). Since the WT C14 2'-OH resonance $(\approx 8.5 \mathrm{ppm})(16)$ is in a crowded region of the $1 \mathrm{D}$ spectrum, a $200 \mathrm{~ms}$ NOESY spectrum was used to confirm the absence of this 2'-OH proton in the dC14 ScYLV RNA (data not shown).

\section{pH-dependence of the unfolding of the WT ScYLV and mutant RNAs}

The unfolding of luteoviral RNA pseudoknots has been investigated previously by thermal unfolding as monitored by UV spectroscopy at 260 and $280 \mathrm{~nm}$ and differential scanning calorimetry $(16,20,26)$. These RNA pseudoknots are composed of a 5 base pair S1 (4 in the case of potato leaf roll virus (PLRV) (19)), a 3 base pair S2, a 2 nucleotide loop L1, and a 7 to 9 nucleotide loop L2. A coupled equilibrium model comprising three sequential, two-state unfolding transitions (Scheme 1) previously established for the BWYV pseudoknot (26) was applied to other wild-type and variant pseudoknots when sufficient resolution of individual unfolding transitions was observed on the temperature coordinate (20). Each equilibrium unfolding step is characterized by a van't Hoff enthalpy of unfolding, $\Delta H_{\mathrm{vH}}$, and a melting temperature, $t_{\mathrm{m}}$, (see Schemes 1,2). In the 3-step unfolding profile, the first unfolding step is assigned to disruption of the loop-stem (L2-S1 and L1-S2) interactions in the fully folded (F) RNA pseudoknot to form PK, which is followed by the unfolding of the weaker stem S2 (S1 $\mathrm{HP}$ ), and subsequently stem S1 (U). In cases where the first two unfolding steps were coincident on the temperature axis and sufficient unfolding enthalpy was recovered under this transition, Scheme 2 was used to analyze the melting profiles. In this scheme. the disruption of the tertiary structural interactions and S2 occurs during the first unfolding transition giving rise to a single S1 HP intermediate (16).

Thermal melting profiles (dA/dT) monitored by UV spectroscopy were obtained for the WT, $\mathrm{dC} 14, \mathrm{C} 27 \mathrm{~A}$ and dC14/C27A ScYLV RNAs at $\mathrm{pH}$ values ranging from 5.0 to $\mathrm{pH} 9.0$ at $0.5 \mathrm{M}$ $\mathrm{KCl}$, the latter used to facilitate comparison with previous studies with the BWYV RNA (see Figs. 3-4) (20). Inspection of these melting profiles reveals that the $t_{\mathrm{m}}$ 's for all transitions excepting the last one are strongly affected by the $\mathrm{pH}$; since the last unfolding transition is reporting on $\mathrm{S} 1$ melting, the $t_{\mathrm{m}}$ is as expected, independent of $\mathrm{pH}$ (data not shown) (16). This is consistent with the unfolding models shown (Schemes 1 and 2) and with protonation of C8 $\mathrm{N} 3$ only in the folded RNA $(16,20,26)$. It is interesting to note that the dC14 RNAs, which destroy single C27 N3-C14 2'-OH and A27 N1-C14 2'-OH hydrogen bonds in WT and C27A 
ScYLV RNAs, respectively, break the coincident unfolding of S2 and tertiary structural interactions that characterize both WT and C27A ScYLV RNAs.

The $\mathrm{pH}$-dependence of folding, $\Delta G_{37}$ as calculated in Materials and Methods, is plotted in Figure 5, filled circles, for the indicated luteoviral RNA with data analyzed by two independent $\mathrm{pH}$-dependent folding models. The first model is a simple binding model (eq. 1) that attributes the entire change in $\Delta G_{37}$ as a function of $\mathrm{pH}$ to protonation of a single group in the folded RNA according to the function

$$
\Delta G_{37, o b s}=\Delta G_{37} \text { unprotonated }+\left(\Delta G_{37^{\text {protonated }}}-\Delta G_{37^{\text {unprotonated }}}\right) \times\left[10^{\left(p K_{a}-p H\right)} /\left(1+10^{\left(p K_{a}-p H\right)}\right)\right]
$$

where $\Delta G_{37}$ unprotonated and $\Delta G_{3} 7^{\text {protonated }}$ represent the $\Delta G_{37}$ values for the fully unprotonated and fully protonated state of the folded RNA molecules, respectively (20). Here, $\mathrm{p} K_{\mathrm{a}}$ is an apparent $\mathrm{p} K_{\mathrm{a}}$ where $K_{\mathrm{a}}$ is equal to the acid dissociation equilibrium constant that governs $\mathrm{C}^{+}$deprotonation. This may not reflect the intrinsic $\mathrm{p} K_{\mathrm{a}}$, since this analysis ignores differential $\mathrm{H}^{+}$binding to the unfolded state relative to the folded state outside of this titratable group, and linkage to acid-induced or alkaline-induced unfolding (see below) (30). The fits to the data are displayed in Figure 5 (continuous line) with the resolved thermodynamic parameters from the fits compiled in Table 1 . As was previously shown, the C27A RNA is destabilized with respect to the WT ScYLV RNA due to the rearrangement of the helical junction by $\approx 1.2 \mathrm{kcal} \cdot \mathrm{mol}^{-1}$ over the entire $\mathrm{pH}$-range (16). The $\Delta G_{3} 7^{\text {protonated }}$ of the dC14 RNA is $0.6 \pm 0.2 \mathrm{kcal} \cdot \mathrm{mol}^{-1}$ less than the WT ScYLV RNA with $\Delta G_{3} 7^{\text {unprotonated }}$ the same within experimental error.

Interestingly, the downward shift for $\mathrm{C} 27 \mathrm{~A}$ in the apparent $\mathrm{p} K_{\mathrm{a}}$ is only 0.4 units, which is much smaller than the 1.6 unit shift previously observed for the dC14 BWYV RNA (20). In contrast

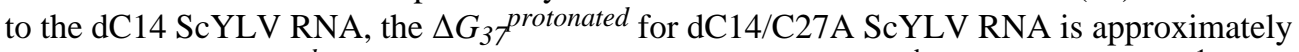
equal to $\Delta G_{3} 7^{\text {protonated }}$ for the reference C27A RNA $\left(\Delta \Delta G^{\text {protonated }}=0.2 \pm 0.3 \mathrm{kcal} \cdot \mathrm{mol}^{-1}\right)$, with the $\Delta G_{37}$ unprotonated more positive by $0.7( \pm 0.3) \mathrm{kcal} \cdot \mathrm{mol}^{-1}$; here, there is a negligible shift in apparent $\mathrm{p} K_{\mathrm{a}}$.

The second model used to fit the $\Delta G_{37}$ vs. $\mathrm{pH}$ data is a linkage model that accounts for linkage of a single protonation site in the folded state to acid-induced denaturation that occurs on protonation of all cytidine $\mathrm{N} 3$ and adenosine $\mathrm{N} 1$ groups in the unfolded state (30). The data were fit to the equation

$$
\Delta G_{f}^{o b s}=\Delta G_{f}^{r e f}-R T \ln \left(\sum_{f} / \sum_{u}\right)
$$

where $\Delta G_{f}^{\text {ref }}$ is the ligand free $\mathrm{U}$ to $\mathrm{F}$ reaction (conceptually analogous to $\Delta G_{37}$ unprotonated in the binding model), and

$$
\begin{gathered}
\sum_{f}=1+10^{\left(p K_{a, f}-p H\right)} \\
\sum_{u}=\left(1+10^{\left(p K_{a, u}^{A}-p H\right)}\right)^{n^{A}}\left(1+10^{\left(p K_{a, u}^{C}-p H\right)}\right)^{n^{C}}
\end{gathered}
$$

where $n^{\mathrm{A}}$ and $n^{\mathrm{C}}$, respectively, equal the number of adenosines and cytidines in the molecule. The $\mathrm{p} K_{\mathrm{a}}$ values for $p K_{a, u}^{A}$ and $p K_{a, u}^{C}$ were fixed to 3.7 and 4.4 , respectively, and represent the intrinsic $\mathrm{p} K_{\mathrm{a}}$ of the $\mathrm{N} 1$ of adenosine and the $\mathrm{N} 3$ of cytosine, respectively (30). This leaves just two fitted parameters, $\mathrm{p} K_{a, f}$ and $\Delta G_{f}^{\text {ref }}$. The two terms, $\Sigma_{f}$ and $\Sigma_{u}$ reflect the sum contributions of protonation in the folded and unfolded states of the RNA. Best-fit curves to the linkage equation are superimposed (dashed lines) on the experimental data (Figure 5) with the $\mathrm{p} K_{a, f}$ 
and $\Delta G_{f}^{r e f}$ values given in Table 1 . As can be seen, the $\Delta G_{37}$ unprotonated and $\Delta G_{f}^{\text {ref }}$ are in reasonably good agreement for all of the RNA molecules. Note that the calculated $\mathrm{p} K_{\mathrm{a}}$ values predicted from the linkage model are significantly higher than those from the binding equation, as expected (30). The linkage equation should better resolve the microscopic $\mathrm{p} K_{\mathrm{a}}$ for protonation of $\mathrm{C}^{+}$in the folded state, provided data are obtained at $\mathrm{pH}$ lower that 5.0, since this is when the two functions strongly diverge from one another; however, this point was not investigated here (30).

\section{Effect of $\mathrm{pH}$ on the unfolding of the dC14 RNAs}

To obtain insight into the effect of $\mathrm{pH}$ on the unfolding of the $\mathrm{dC} 14$ RNAs relative to the WT and C27A RNA counterparts, $\Delta \Delta G_{37}$ was calculated for the binding model (eq. 5) and linkage model (eq. 6) and the simulated curves, derived from the parameter values compiled in Table 1 , superimposed on the experimental data, $\Delta \Delta G_{37} \exp$ (Figure 6).

$$
\begin{gathered}
\Delta \Delta G_{37, o b s}(p H)=\Delta G_{37, o b s}^{\text {deoxy } 14}(p H)-\Delta G_{37, o b s}^{W T}(p H) \\
\Delta \Delta G_{f}^{o b s}(p H)=\Delta G_{f}^{o b s, \text { deoxyC } 14}(p H)-\Delta G_{f}^{o b s, W T}(p H)
\end{gathered}
$$

Although there is significant scatter given the small $\Delta \Delta G_{37}$ values, the simulated curves generated from the binding model capture the general trends in the experimental data reasonably well (Fig. 6A). In contrast, the simulated curve generated from the linkage model approximates the data less well (Fig. 6B). The reason for this is embodied in the function (eq. 2) itself which reduces to

$$
\Delta \Delta G_{f}^{o b s}(p H)=\Delta \Delta G_{f}^{r e f}-R T \ln \left(\sum_{f}^{m u t} / \sum_{f}^{W T}\right)
$$

where $\Delta \Delta G_{f}^{r e f}=\Delta G_{f}^{r e f, m u t}-\Delta G_{f}^{r e f, W T}$ provided $\sum_{u}^{W T}=\sum_{u}^{m u t}$. This is a reasonable assumption since the two RNAs are the same length and have the identical base compositions (the same number of $\mathrm{A}$ and $\mathrm{C}$ residues), and differ only by a single oxygen atom. When mutant and WT RNAs have identical $\mathrm{p} K_{\mathrm{a}}$ values, the second term in eq. 7 vanishes, reducing to $\Delta \Delta G_{f}^{o b s}(p H)=\Delta \Delta G_{f}^{\text {ref }}$, i.e., a straight line. In the case where $\mathrm{p} K_{\mathrm{a}}{ }^{\mathrm{mut}} \neq \mathrm{p} K_{\mathrm{a}}{ }^{\mathrm{WT}}$ the function $\Delta \Delta G_{f}^{o b s}(p H)$ is strictly monotonic, i.e. always increasing or decreasing.

\section{Pairwise coupling, $\delta_{A B}$, across the helical junction in WT vs. C27A ScYLV pseudoknots}

A standard double mutant cycle strategy was next employed to obtain $\delta_{\mathrm{AB}}{ }^{\mathrm{WT}}$ and $\delta_{\mathrm{AB}} \mathrm{C} 27 \mathrm{~A}$ using the $\mathrm{WT} \cdot \mathrm{H}+$ as the overall system reference state (see Fig. 7). $\delta_{\mathrm{AB}}{ }^{\mathrm{WT}}$ is the pairwise coupling free energy that defines the extent to which elimination of both $\mathrm{C} 27 \mathrm{~N} 3-\mathrm{C} 142^{\prime}-\mathrm{OH}$ (via the deoxyC14 substitution) and $\mathrm{C}^{+} \mathrm{H} 3-\mathrm{G} 12 \mathrm{O} 6$ (via raising the $\mathrm{pH}$ ) hydrogen bonds in the WT ScYLV RNA ( $\triangle G_{\mathrm{AB}}{ }^{\mathrm{WT}}$ ) differs from the sum of the loss of each hydrogen bond individually ( $\Delta G_{\mathrm{A}}{ }^{\mathrm{WT}}$ and $\Delta G_{\mathrm{B}}{ }^{\mathrm{WT}}$, respectively) (31). Likewise, $\delta_{\mathrm{AB}}{ }^{\mathrm{C} 27 \mathrm{~A}}$ defines the analogous free energy difference for the C27A ScYLV pseudoknot, i.e., loss of the A27 N1$\mathrm{C} 142^{\prime}-\mathrm{OH}\left(\Delta G_{\mathrm{A}}{ }^{\mathrm{C} 27 \mathrm{~A}}\right)$ and $\mathrm{C} 8{ }^{+} \mathrm{H} 3-\mathrm{G} 12 \mathrm{O} 6\left(\Delta G_{\mathrm{B}}{ }^{\mathrm{C} 27 \mathrm{~A}}\right)$ hydrogen bonds individually or in combination $\left(\Delta G_{\mathrm{AB}}{ }^{\mathrm{C} 27 \mathrm{~A}}\right) \cdot \delta_{\mathrm{AB}}{ }^{i}$ is therefore defined as

$$
\delta_{\mathrm{AB}}^{i}=\Delta G_{\mathrm{AB}}^{i}-\left(\Delta G_{\mathrm{A}}^{i}+\Delta G_{\mathrm{B}}^{i}\right)
$$

$\Delta G_{\mathrm{A}}{ }^{i}, \Delta G_{\mathrm{B}} i$ and $\Delta G_{\mathrm{AB}}{ }^{i}$ are obtained by manipulation of $\Delta G_{37}$ protonated for $\mathrm{WT} \cdot \mathrm{H}+, \mathrm{dC} 14 \cdot \mathrm{H}$ ,$+ \mathrm{C} 27 \mathrm{~A} \cdot \mathrm{H}+$ and $\mathrm{dC} 14-\mathrm{C} 27 \mathrm{~A} \cdot \mathrm{H}+\mathrm{ScYLV}$ RNAs, i.e., the RNA species on the left side of the 
thermodynamic cube (Fig. 7). and $\Delta G_{3} 7^{\text {unprotonated }}$ for the same four deprotonated RNAs, i.e., those on the right side of the thermodynamic cube (Fig. 7). These $\Delta G_{3} 7^{\text {protonated }}$ and $\Delta G_{37}{ }^{\text {unprotonated }}$ values are compiled in Table 1 and reproduced on the thermodynamic cube in Fig. 7 (in italics). For example, $\Delta G_{\mathrm{A}} \mathrm{WT}^{\mathrm{WT}}=-5.9-(-6.5)=0.6 \mathrm{kcal} \mathrm{mol}^{-1}, \Delta G_{\mathrm{B}} \mathrm{WT}=-3.5-$ $(-6.5)=3.0 \mathrm{kcal} \mathrm{mol}^{-1}$, and $\Delta G_{\mathrm{AB}} \mathrm{WT}^{\mathrm{WT}}=-3.6-(-6.5)=2.9 \mathrm{kcal} \mathrm{mol}^{-1}$. Thus, $\delta_{\mathrm{AB}}{ }^{\mathrm{WT}}=2.9-(3.0$ $+0.6)=-0.7 \mathrm{kcal} \mathrm{mol}^{-1}$ reflecting a favorable pairwise coupling free energy and indicative of positive cooperativity of hydrogen bond formation $\left(\delta_{\mathrm{AB}}{ }^{i}<0\right)$ (see Table 2). Note that if $\delta_{\mathrm{AB}}{ }^{i}$ $=0$, then $\Delta G_{\mathrm{AB}}{ }^{i}=\Delta G_{\mathrm{A}}{ }^{i}+\Delta G_{\mathrm{B}}{ }_{\mathrm{i}}^{\mathrm{i}}$. In this case, formation of each hydrogen bond is additive or non-cooperative, and the loss of the A or B interaction is not influenced by the loss of the remaining interaction at site $\mathrm{B}$ or $\mathrm{A}$, respectively. If $\delta_{\mathrm{AB}}{ }^{i}>0$, the pairwise coupling is unfavorable and formation of both hydrogen bonds is non-additive. $\Delta G_{\mathrm{A}}{ }^{i}, \Delta G_{\mathrm{B}}{ }^{i}, \Delta G_{\mathrm{AB}}{ }^{i}$ and $\delta_{\mathrm{AB}}{ }^{\mathrm{WT}}$ and $\delta_{\mathrm{AB}}{ }^{\mathrm{C} 27 \mathrm{~A}}$ values calculated in this way are compiled in Table 2, as are the corresponding values obtained from a similar analysis of the closely related BWYV and dC14 BWYV pseudoknots published previously (20). Interestingly, both $\delta_{\mathrm{AB}}{ }^{\mathrm{WT}}$ and $\delta_{\mathrm{AB}}{ }^{\mathrm{BWYV}}$ are significantly negative, indicative of positively cooperative formation of these two hydrogen bonds that straddle the helical junction. In contrast, $\delta_{\mathrm{AB}}{ }^{\mathrm{C} 27 \mathrm{~A}}$ has a positive sign, indicative of non-additivity of hydrogen bond formation across the helical junction. This finding is consistent with the free energy cycles that yield $\delta_{\mathrm{AB}}{ }^{\mathrm{C} 8+}$ and $\delta_{\mathrm{AB}}{ }^{\mathrm{C} 8}$ (Fig. 7, left and right). $\delta_{\mathrm{AB}}{ }^{\mathrm{C} 8+}$ and $\delta_{\mathrm{AB}}{ }^{\mathrm{C} 8}$ are equal to -0.8 and $+0.8 \mathrm{kcal} \mathrm{mol}^{-1}$, respectively (see Table 2 ), and reflects the extent to which perturbation of the H-bond donor (dC14) and acceptor (C27A) sides of the same C27 N3-C14 2'-OH hydrogen bond, individually and in combination, is influenced by protonation of immediately adjacent $\mathrm{C} 8$. At low $\mathrm{pH}$, this coupling is favorable $\left(\delta_{\mathrm{AB}} \mathrm{C} 8+<0\right)$, i.e., the folding free energy of the double mutant is less negative then the sum of each of the underlying single mutants, with the opposite true at high $\mathrm{pH}$ in the deprotonated forms of the RNA $\left(\delta_{\mathrm{AB}}{ }^{\mathrm{C}}>0\right)$. Finally, using the WT.H+ conformation as the reference state for the thermodynamic cube, and denoting $\Delta G_{\mathrm{C}} \mathrm{WT}^{\mathrm{WT}} \Delta \Delta G^{\text {protonated }}$ for the C27A vs. WT ScYLV RNAs and $\Delta G_{\mathrm{ABC}} \mathrm{WT}^{\mathrm{WT}} \Delta \Delta G^{\text {protonated }}$ for the $\mathrm{dC} 14 / \mathrm{C} 27 \mathrm{~A}$ vs. WT RNAs (and $\Delta G_{\mathrm{A}}^{\mathrm{WT}}$ and $\Delta G_{\mathrm{B}}{ }^{\text {WT }}$ defined as above) one can also calculate the three-way coupling in this system, $\Delta G^{3}$, according to:

$$
\Delta G^{3}=\Delta G_{\mathrm{ABC}}{ }^{\mathrm{WT}}-\left[\left(\Delta G_{\mathrm{A}}{ }^{\mathrm{WT}}+\Delta G_{\mathrm{B}}{ }^{\mathrm{WT}}+\Delta G_{\mathrm{C}}{ }^{\mathrm{WT}}\right)+\sum \delta_{\mathrm{AB}}{ }^{i}\right]
$$

where $\Delta G^{3}$ is equal to the folding free energy of the triple substitution mutant dC14/C27A RNA at high $\mathrm{pH}, \Delta G_{\mathrm{ABC}}{ }^{\mathrm{WT}}$, minus the sum of the folding free energies of the single mutants and each of the six pairwise couplings, $\delta_{\mathrm{AB}}{ }^{i}$ (Table 2). $\Delta G^{3}$ is $-1.8 \mathrm{kcal} \mathrm{mol}^{-1}$, which is indicative of a strong coupling network in the WT ScYLV RNA.

\section{Effect of $\mathrm{pH}$ on $\delta_{A B}{ }^{W T}, \delta_{A B}{ }^{C 27 A}$ and $\delta_{A B}{ }^{B W Y V}$ values}

This coupling analysis is completely independent of $\mathrm{p} K_{\mathrm{a}}$ since the states selected were derived from $\Delta G^{\text {protonated }}$ and $\Delta G^{\text {deprotonated }}$ measured at low and high $\mathrm{pH}$, respectively. To understand the effect of $\mathrm{pH}$ on the three pairwise couplings $\delta_{\mathrm{AB}}{ }^{i}\left(\delta_{\mathrm{AB}}{ }^{\mathrm{WT}}, \delta_{\mathrm{AB}}{ }^{\mathrm{C} 27 \mathrm{~A}}\right.$ and $\left.\delta_{\mathrm{AB}}{ }^{\mathrm{BWYV}}\right)$, the coupling scheme was modified to correct for the concentration of reference state molecules, i.e., WT. $\mathrm{H}^{+}, \mathrm{C} 27 \mathrm{~A} \cdot \mathrm{H}^{+}$or BYWV$\cdot \mathrm{H}^{+}$, at each $\mathrm{pH}$. Here, the equations change to

$$
\begin{gathered}
\Delta G_{A B}^{e f f}(p H)=\left(\Delta G_{37}^{\text {unprotonated,deoxyC } 14}\right)\left([H A]^{\text {deoxy } C 14}\right)-\Delta G_{37, o b s}^{W T}(p H)\left([H A]^{W T}\right) \\
\Delta G_{A}^{\text {eff }}(p H)=\left(\Delta G_{37, o b s}^{\text {deoxy } C 14}(p H)\right)\left([H A]^{\text {deoxyC } 14}\right)-\Delta G_{37, o b s}^{W T}(p H)\left([H A]^{W T}\right) \\
\Delta G_{B}^{e f f}(p H)=\left(\Delta G_{37}^{\text {unprotonated }, W T}-\Delta G_{37, o b s}^{W T}(p H)\right)\left([H A]^{W T}\right) \\
{\left[H A^{X}\right]=1 /\left(1+10^{p H-p K_{a}{ }^{X}}\right)}
\end{gathered}
$$


for the binding model, allowing us to define a new term, $\delta_{\mathrm{AB}}{ }^{i, e f f}(\mathrm{pH})$, the effective pairwise coupling as a function of $\mathrm{pH}$, according to:

$$
\delta_{\mathrm{AB}}^{i, e f f}(\mathrm{pH})=\Delta G_{\mathrm{AB}}{ }^{i, e f f}(\mathrm{pH})-\left[\Delta G_{\mathrm{A}}^{i, e f f}(\mathrm{pH})+\Delta G_{\mathrm{B}}{ }^{i, e f f}(\mathrm{pH})\right]
$$

Exactly analogous expressions were derived for the linkage model (see eqs. 2-4), using p $K_{\mathrm{a}}$ and $\Delta G_{f}^{r e f}$ parameters resolved from the linkage model fits (Table 1, italicized parameters). Plots of $\delta_{\mathrm{AB}}$ i,eff as a function of $\mathrm{pH}$ are presented as simulated curves using parameters derived from the binding model (Fig. 8A) and linkage model (Fig. 8B). As expected, at low pH, $\delta_{\mathrm{AB}}{ }^{i, e f f}(\mathrm{pH})=\delta_{\mathrm{AB}}{ }^{i}$ (from Table 2 ) for each RNA; this occurs as a result of taking the $\mathrm{WT} \cdot \mathrm{H}^{+}, \mathrm{C} 27 \mathrm{~A} \cdot \mathrm{H}^{+}$or BYWV$\cdot \mathrm{H}^{+}$as the reference state in each case. In Fig. $8 \mathrm{~A}, \delta_{\mathrm{AB}}$ i,eff first goes more negative or favorable for the WT ScYLV (continuous line) and BWYV (dotted line) RNAs; the depth of this trough is essentially determined by the difference in binding $\mathrm{p} K_{\mathrm{a}}$ ' $\mathrm{s}$ between the WT and dC14-containing RNAs, which is greater for the BWYV RNA (see Table 1) (20). As the $\mathrm{pH}$ is further increased, $\delta_{\mathrm{AB}}{ }^{i, e f f}$ becomes less negative and vanishes altogether at $\mathrm{pH} \geq 8.0$, fully expected since the concentration of protonated RNA molecules becomes very small at high $\mathrm{pH}$. The situation is dramatically different for the C27A ScYLV RNA, where $\delta_{\mathrm{AB}}{ }^{i, e f f}$ is positive or unfavorable at all $\mathrm{pH}$ values, until vanishing as expected at high $\mathrm{pH}$ (Fig. 8A, dashed line). Roughly similar trends in the simulated curves are obtained with the linkage model-derived parameters (Fig. 8B), except that there are no troughs since eq. [7] is monotonic, and $\delta_{\mathrm{AB}}{ }^{i, e f f}$ vanishes at significantly higher $\mathrm{pH}$ values due to the higher $\mathrm{p} K_{\mathrm{a}}$ 's derived from this analysis (Table 1).

Fig. 8C shows the results of plotting $\Delta \delta_{\mathrm{AB}}$, eff , defined as $\delta_{\mathrm{AB}}{ }^{\mathrm{WT}}-\delta_{\mathrm{AB}}{ }^{\mathrm{C} 27 \mathrm{~A}}$, derived from the binding (solid line) and linkage (dashed line) model parameters compared to the experimental global $\Delta \Delta G_{37}$ measured as a function of $\mathrm{pH}$ (16). This is a measure of the degree to which the relative differences in pairwise coupling free energies across the helical junction measured for the wild-type and C27A RNAs track with global differences in stability between the two RNAs. Although the trends in $\Delta \Delta G_{37}$ do not show a simple $\mathrm{pH}$-dependence, the average value of $\Delta \Delta G_{37}\left(-1.1 \pm 0.3 \mathrm{kcal} \mathrm{mol}^{-1}\right.$, dashed line) is of the same sign and magnitude, and well within the simulated values of $\Delta \delta_{\mathrm{AB}}$, eff over the entire $\mathrm{pH}$ range, with $\Delta \delta_{\mathrm{AB}}$, eff more negative than $\Delta \Delta G_{37}$ at $\mathrm{pH}<7$, and less negative at higher $\mathrm{pH}$ values. This is particularly so considering a conservative estimate of $\pm 0.5 \mathrm{kcal} \mathrm{mol}^{-1}$ uncertainty in the experimental values of $\Delta \delta_{\text {eff }} i$ particularly at low $\mathrm{pH}$ (see Table 2 ). These data are therefore generally consistent with the idea that much of the global $\Delta \Delta G_{37}$ can be traced to an altered pairwise coupling of these two cross junction hydrogen bonds between functional (WT) and poorly functional (C27A) ScYLV RNA pseudoknots. This is fully consistent with the structures of these two RNAs $(16,23)$.

\section{Discussion}

In this paper, we have determined the extent to which two key adjacent tertiary structural hydrogen bonds that cross the helical junction form cooperatively in three H-type RNA pseudoknots for which structures and frameshift stimulation activities (at pH 7.0) are known. The most striking finding from this study is that in the context of the two most conservative substitutions that can be introduced, i.e., the loss of the $\mathrm{H}$-bond donor in each of the two hydrogen bonds ( $\mathrm{C} 142^{\prime}-\mathrm{OH}$ to $2^{\prime}-\mathrm{H}$; $\mathrm{C} 8 \mathrm{~N} 3-\mathrm{H}+$ to $\mathrm{N} 3$ ) individually or in combination, the WT $\operatorname{ScYLV}\left(\delta_{\mathrm{AB}}{ }^{\mathrm{WT}}\right)$ and WT BWYV $\left(\delta_{\mathrm{AB}}{ }^{\mathrm{BWYV}}\right)$ RNAs exhibit favorable pairwise coupling free energies (Table 2) indicative of cooperative hydrogen bond formation while the poorly functional C27A ScYLV RNA $\left(\delta_{\mathrm{AB}}{ }^{\mathrm{C} 27 \mathrm{~A}}\right)$ is characterized by an unfavorable coupling, or nonadditive hydrogen bond formation. This is the case despite the fact that the helical junction region of the C27A ScYLV RNA is more like that of the BWYV RNA relative to the wildtype ScYLV RNA (see Fig. 1) (23). 
This result reveals that the energetics of pairwise hydrogen bond coupling is not well predicted by the global structure alone, but it is instead strongly influenced by the context in which these interactions are made. An implicit assumption in any pairwise coupling experiment is that the structures of the molecule lacking one or both hydrogen bonds are essentially identical and all that is missing is the hydrogen bond itself and the energetic consequences that derive from deleting it. Since hydrogen bond strength is influenced by hydrogen bond geometry (length and angle), the extent to which formation of two hydrogen bonds is pairwise coupled could also be influenced by small structural differences among all four RNAs at low vs. high pH. Very high resolution structures of these RNAs under a variety of solution conditions would be required to address this. In fact, introduction of a single deoxyribose substitution in an otherwise all-RNA context may also perturb the sugar pucker from C3'-endo (N-type) to C2'endo (S-type) (32), albeit to varying degrees, which might indirectly influence the magnitude of hydrogen bond coupling by perturbing the local structure. However, this is clearly not the case here since NMR data clearly reveal that the dC14 sugar pucker adopts a C3'-endo conformation, like C14 in the WT RNA (16). ${ }^{1}$ In general, the measured pairwise coupling free energy may not be direct and the presence or absence of specific interactions in the BWYV vs. C27A ScYLV RNAs may play a role in determining the magnitude and sign of the pairwise coupling free energy. One way to establish whether a measured pairwise coupling free energy is direct or indirect is to introduce a mutation or substitution into a third site and ${ }^{i}$ be re-evaluated (31). If the two values of $\delta_{\mathrm{AB}}{ }^{i}$ are not equal, then the $\mathrm{AB}$ pairwise coupling is indirect, thus providing evidence for a more complex network of thermodynamically coupled or cooperative interactions. In this regard, it is important to further consider the structural differences between the C27A ScYLV and BWYV RNAs. Comparison of Figs. 1C and 1D reveals that the helical junction of the C27A ScYLV RNA is more strongly over-rotated than the BWYV RNA, which results in poorer stacking of the two junction triple base pairs; this in turn, might influence the degree of pairwise coupling of junction hydrogen bonds in these two RNAs. However, this cannot be the sole reason for the different $\delta_{\mathrm{AB}}{ }^{i}$ since the WT ScYLV RNA is even more poorly stacked than in the C27A RNA (see Fig. 1B-C).

The other structural difference between the BWYV and C27A ScYLV RNAs is that the ScYLV pseudoknot contains an extrahelical nucleotide, C25, which is not present in the BWYV RNA. The presence or absence of this nucleotide might influence the magnitude of $\delta_{\mathrm{AB}}{ }^{i}$ via a next nearest neighbor influence on the packing of A26 into the minor groove triplex, as well as the adjacent A24.(G6-C15) base triple; clearly, the integrity of the nucleotide analogous to A26 in the ScYLV pseudoknot is important for luteoviral pseudoknot stability $(19,20,33)$.

Interestingly, deletion of C25 in ScYLV RNAs consistently increases frameshift stimulation by $\approx 2$-fold in a variety of structural contexts; simultaneous deletion of C25 with one other L2 nucleotide increases frameshift-stimulation by the C27A RNA 3-fold, resulting in a functional activity indistinguishable from the wild-type BWYV RNA (16). If the magnitude and sign of $\delta_{\mathrm{AB}}{ }^{i}$ track with frameshifting activity, this makes the prediction that the $\triangle \mathrm{C} 25$ and this BWYVlike ScYLV mutant would yield very different $\delta_{\mathrm{AB}}{ }^{i}$ relative to the C27A and WT ScYLV pseudoknots. These experiments are currently in progress.

Upon encountering a programmed mRNA frameshift signal, the decoding ribosome is thought to pause and shift reading frames without dissociation, and continue decoding in the new reading frame. The pseudoknot has to be stable enough to resist mechanical unwinding by the elongating ribosome in a kinetically relevant rate, but not too stable as to induce dissociation

\footnotetext{
${ }^{1} \mathrm{~A}$ NOESY spectrum ( $\tau_{\mathrm{m}}=120 \mathrm{~ms}$ ) acquired in $\mathrm{D}_{2} \mathrm{O}$ was used to assign the $\mathrm{H} 1^{\prime}(5.67 \mathrm{ppm}), \mathrm{H} 2^{\prime}(2.70 \mathrm{ppm})$, and $\mathrm{H} 2^{\prime \prime}$ (3.36 ppm) protons of dC14. Only the sequential dC14 H2'-C15 H6 NOE is clearly observed in this spectrum with the dC14 H2"-C15 H6 NOE not readily detected. In addition, there are no detectable $\mathrm{dC} 14 \mathrm{H} 1^{\prime}-\mathrm{H} 2^{\prime}$ or $\mathrm{H} 1^{\prime}-\mathrm{H} 2^{\prime \prime}$ correlations in the TOCSY spectrum under conditions where sugars with known C2' endo puckers give intense correlations, e.g., U19 (spectra not shown). All of these data are fully consistent with the conclusion that the dC14 sugar adopts a $\mathrm{C}^{\prime}$ ' endo conformation in the dC14 RNA..
} 
of the translation elongation complex. In this way of thinking, the pseudoknot provides a kinetic barrier to ribosome-mediated unfolding (and/or refolding). The studies reported here extend our previous structural work on this system, and support the hypothesis that those helical junctions with favorable $\delta_{\mathrm{AB}}{ }^{i}$ may well resist ribosome-mediated resolution of the pseudoknot more effectively than those characterized by less favorable or unfavorable $\delta_{\mathrm{AB}}{ }^{i}$ since these would likely lower the kinetic barrier to ribosome-mediated unwinding. In this regard, it will be of interest to investigate hydrogen bond coupling throughout the molecule. For example, although deletion of the 2 '-OH protons of $\mathrm{C} 15$ or A16 riboses might be predicted to have a significant impact on global stability (20), it would be of interest to determine how the magnitude of $\delta_{\mathrm{AB}}{ }^{i}$ is affected by deoxynucleotide substitutions further from the $\mathrm{C} 8^{+}$. (G12$\mathrm{C} 28$ ) major groove base triple. This would provide insight into the cooperativity of the loopstem interactions in frameshifting RNAs. Finally, we note that the magnitude of the pairwise coupling as operationally defined here is dependent on $\mathrm{pH}$, making the prediction that the efficiency of frameshifting induced by luteoviral pseudoknots might also be influenced by the $\mathrm{pH}$. Experiments along these lines are currently in progress.

\section{Supplementary Material}

Refer to Web version on PubMed Central for supplementary material.

\section{Acknowledgements}

We thank Suzanne Stammler and Dr. Xiangming Kong for acquiring the NMR spectra of dC14 ScYLV RNA. We also gratefully acknowledge Professor J. Martin Scholtz for helpful suggestions during the course of this work and for offering comments on the manuscript.

\section{References}

1. Kervestin S, Amrani N. Translational regulation of gene expression. Genome Biol 2004;5:359. [PubMed: 15575982]

2. Tucker BJ, Breaker RR. Riboswitches as versatile gene control elements. Curr Opin Struct Biol 2005;15:342-348. [PubMed: 15919195]

3. Baranov PV, Gesteland RF, Atkins JF. Recoding: translational bifurcations in gene expression. Gene 2002;286:187-201. [PubMed: 11943474]

4. Stahl G, McCarty GP, Farabaugh PJ. Ribosome structure: revisiting the connection between translational accuracy and unconventional decoding. Trends Biochem Sci 2002;27:178-183. [PubMed: 11943544]

5. Felsenstein KM, Goff SP. Expression of the gag-pol fusion protein of Moloney murine leukemia virus without gag protein does not induce virion formation or proteolytic processing. J Virol 1988;62:2179_ 2182. [PubMed: 2452901]

6. Dinman JD, Wickner RB. Ribosomal frameshifting efficiency and gag/gag-pol ratio are critical for yeast M1 double-stranded RNA virus propagation. J Virol 1992;66:3669-3676. [PubMed: 1583726]

7. Biswas P, Jiang X, Pacchia AL, Dougherty JP, Peltz SW. The human immunodeficiency virus type 1 ribosomal frameshifting site is an invariant sequence determinant and an important target for antiviral therapy. J Virol 2004;78:2082-2087. [PubMed: 14747573]

8. Hung M, Patel P, Davis S, Green SR. Importance of ribosomal frameshifting for human immunodeficiency virus type 1 particle assembly and replication. J Virol 1998;72:4819-4824. [PubMed: 9573247]

9. Shehu-Xhilaga M, Crowe SM, Mak J. Maintenance of the Gag/Gag-Pol ratio is important for human immunodeficiency virus type 1 RNA dimerization and viral infectivity. J Virol 2001;75:1834-1841. [PubMed: 11160682]

10. Giedroc DP, Theimer CA, Nixon PL. Structure, stability and function of RNA pseudoknots involved in stimulating ribosomal frameshifting. J Mol Biol 2000;298:167-185. [PubMed: 10764589] 
11. Brierley I, Jenner AJ, Inglis SC. Mutational analysis of the "slippery-sequence" component of a coronavirus ribosomal frameshifting signal. J Mol Biol 1992;227:463-479. [PubMed: 1404364]

12. Yusupova GZ, Yusupov MM, Cate JH, Noller HF. The path of messenger RNA through the ribosome. Cell 2001;106:233-241. [PubMed: 11511350]

13. Takyar S, Hickerson RP, Noller HF. mRNA helicase activity of the ribosome. Cell 2005;120:49-58. [PubMed: 15652481]

14. Plant EP, Jacobs KL, Harger JW, Meskauskas A, Jacobs JL, Baxter JL, Petrov AN, Dinman JD. The 9-A solution: how mRNA pseudoknots promote efficient programmed -1 ribosomal frameshifting. RNA 2003;9:168-174. [PubMed: 12554858]

15. Smith, HG.; Barker, H. The Luteoviridae. 1. CABI Publishing; New York: 1999.

16. Cornish PV, Hennig M, Giedroc DP. A loop 2 cytidine-stem 1 minor groove interaction as a positive determinant for pseudoknot-stimulated -1 ribosomal frameshifting. Proc Natl Acad Sci U S A 2005;102:12694-12699. [PubMed: 16123125]

17. Nixon P, Rangan A, Kim Y, Rich A, Hoffman D, Hennig M, Giedroc D. Solution structure of a luteoviral P1-P2 frameshifting mRNA pseudoknot. J Mol Biol 2002;322:621-633. [PubMed: 12225754]

18. Su L, Chen L, Egli M, Berger JM, Rich A. Minor groove RNA triplex in the crystal structure of a ribosomal frameshifting viral pseudoknot. Nat Struct Biol 1999;6:285-292. [PubMed: 10074948]

19. Pallan PS, Marshall WS, Harp J, Jewett FC III, Wawrzak Z, Brown BA II, Rich A, Egli M. Crystal Structure of a Luteoviral RNA Pseudoknot and Model for a Minimal Ribosomal Frameshifting Motif (,). Biochemistry 2005;44:11315-11322. [PubMed: 16114868]

20. Nixon PL, Cornish PV, Suram SV, Giedroc DP. Thermodynamic analysis of conserved loop-stem interactions in P1-P2 frameshifting RNA pseudoknots from plant Luteoviridae. Biochemistry 2002;41:10665-10674. [PubMed: 12186552]

21. Kim YG, Maas S, Wang SC, Rich A. Mutational study reveals that tertiary interactions are conserved in ribosomal frameshifting pseudoknots of two luteoviruses. RNA 2000;6:1157-1165. [PubMed: 10943894]

22. Kim YG, Su L, Maas S, O'Neill A, Rich A. Specific mutations in a viral RNA pseudoknot drastically change ribosomal frameshifting efficiency. Proc Natl Acad Sci U S A 1999;96:14234-14239. [PubMed: 10588689]

23. Cornish PV, Stammler SN, Giedroc DP. The global structures of a wild-type and poorly functional plant luteoviral mRNA pseudoknot are essentially identical. Submitted for publication

24. Chen X, Chamorro M, Lee SI, Shen LX, Hines JV, Tinoco I Jr, Varmus HE. Structural and functional studies of retroviral RNA pseudoknots involved in ribosomal frameshifting: nucleotides at the junction of the two stems are important for efficient ribosomal frameshifting. EMBO J 1995;14:842852. [PubMed: 7882986]

25. Brierley I, Rolley NJ, Jenner AJ, Inglis SC. Mutational analysis of the RNA pseudoknot component of a coronavirus ribosomal frameshifting signal. J Mol Biol 1991;220:889-902. [PubMed: 1880803]

26. Nixon PL, Giedroc DP. Energetics of a strongly pH dependent RNA tertiary structure in a frameshifting pseudoknot. J Mol Biol 2000;296:659-671. [PubMed: 10669615]

27. Theimer CA, Giedroc DP. Equilibrium unfolding pathway of an H-type RNA pseudoknot which promotes programmed -1 ribosomal frameshifting. J Mol Biol 1999;289:1283-1299. [PubMed: 10373368]

28. Theimer CA, Giedroc DP. Contribution of the intercalated adenosine at the helical junction to the stability of the gag-pro frameshifting pseudoknot from mouse mammary tumor virus. RNA 2000;6:409-421. [PubMed: 10744025]

29. Leontis NB, Stombaugh J, Westhof E. The non-Watson-Crick base pairs and their associated isostericity matrices. Nucleic Acids Res 2002;30:3497-3531. [PubMed: 12177293]

30. Moody EM, Lecomte JT, Bevilacqua PC. Linkage between proton binding and folding in RNA: a thermodynamic framework and its experimental application for investigating pKa shifting. RNA 2005;11:157-172. [PubMed: 15659356]

31. Moody EM, Bevilacqua PC. Folding of a stable DNA motif involves a highly cooperative network of interactions. J Am Chem Soc 2003;125:16285-16293. [PubMed: 14692769] 
32. Lindqvist M, Sarkar M, Winqvist A, Rozners E, Stromberg R, Graslund A. Optical spectroscopic study of the effects of a single deoxyribose substitution in a ribose backbone: implications in RNARNA interaction. Biochemistry 2000;39:1693-1701. [PubMed: 10677217]

33. Egli M, Minasov G, Su L, Rich A. Metal ions and flexibility in a viral RNA pseudoknot at atomic resolution. Proc Natl Acad Sci U S A 2002;99:4302-4307. [PubMed: 11904368] 
A
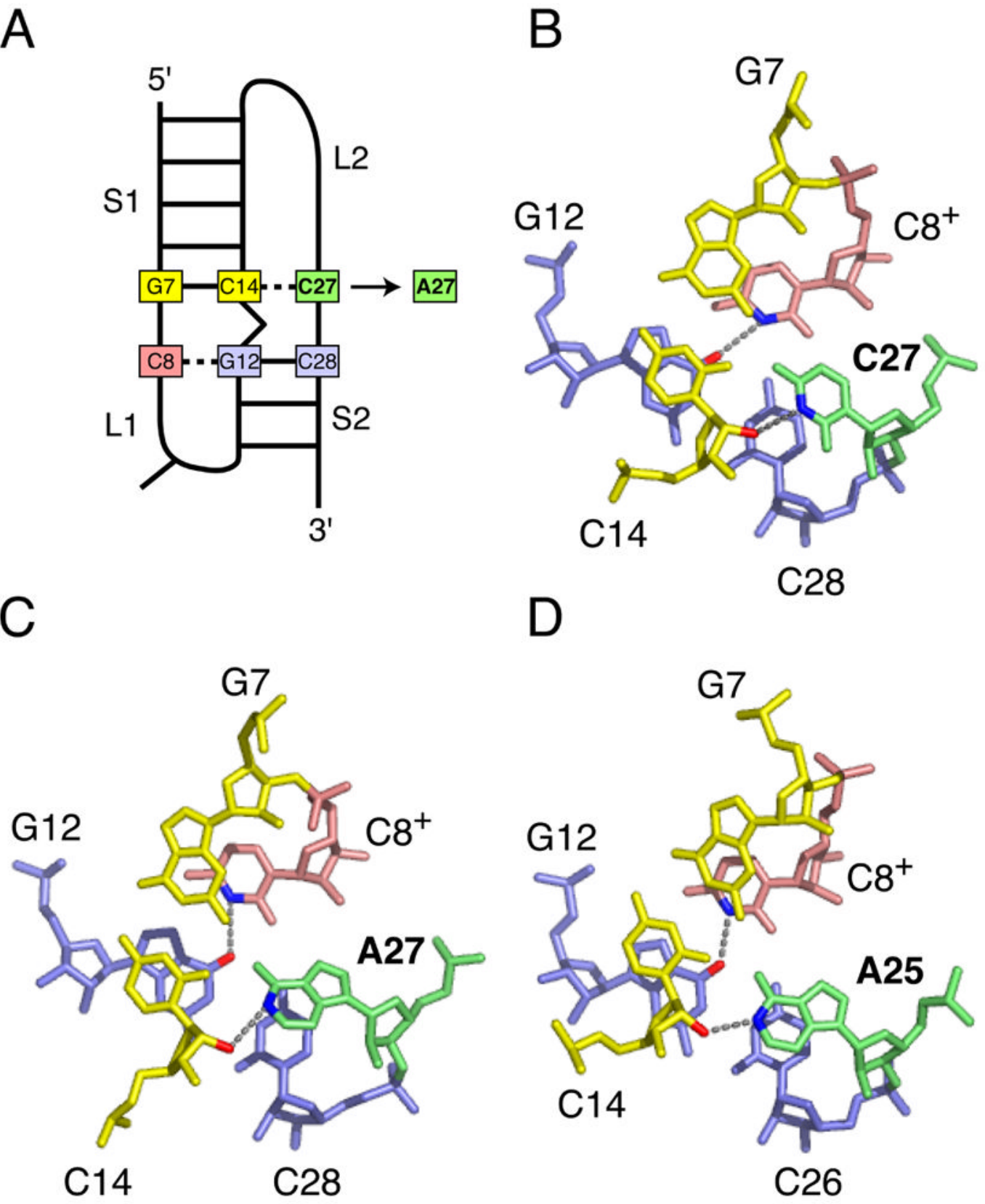

Figure 1.

Helical junction regions of the WT ScYLV, C27A ScYLV and BWYV frameshift-stimulating RNA pseudoknots. (A) Schematic representation of the WT ScYLV RNA pseudoknot. The non-canonical hydrogen bonding interactions investigated in this study are the trans WatsonCrick/Hoogsteen interaction between C8 (shaded pink) and G12 (blue) and the cis WatsonCrick/sugar edge interaction between $\mathrm{C} 27$ (or A27) (green) and C14 (yellow). (B-D) The structures of the helical junction regions of the WT ScYLV (16) (pdb code 1YG4), C27A ScYLV (23) (2AP5), and WT BWYV (1L2X) RNA pseudoknots, respectively, with residues shaded as in panel A. The dashed lines in each panel connect the donor and acceptor atoms of the two hydrogen bonds investigated in this study. 


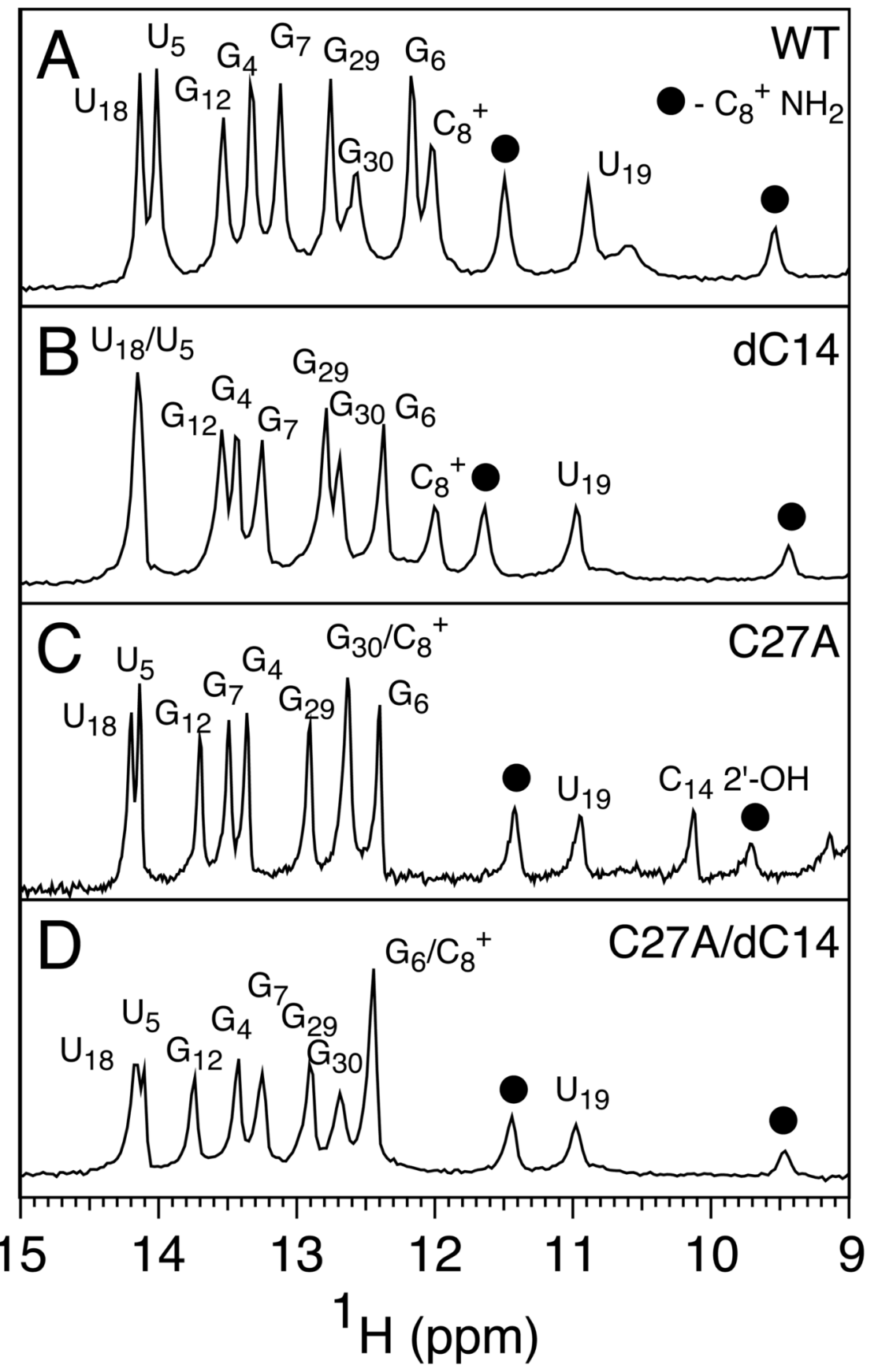

Figure 2.

Downfield region of jump-return echo 1D NMR spectra measured at $10{ }^{\circ} \mathrm{C}$ and $\mathrm{pH} 6.0$ for the WT ScYLV (16) (A), dC14 ScYLV (B), C27A ScYLV (16) (C), and dC14/C27A ScYLV (D) RNAs. All four RNAs show resonances for the protonated $\mathrm{C} 8^{+} \mathrm{N} 3 \mathrm{H}$ and downfield shifted $\mathrm{C}^{+} \mathrm{NH}_{2}$ protons $(\bullet)$ diagnostic of the major groove trans Watson-Crick/Hoogsteen base pair $(16,17)$. 


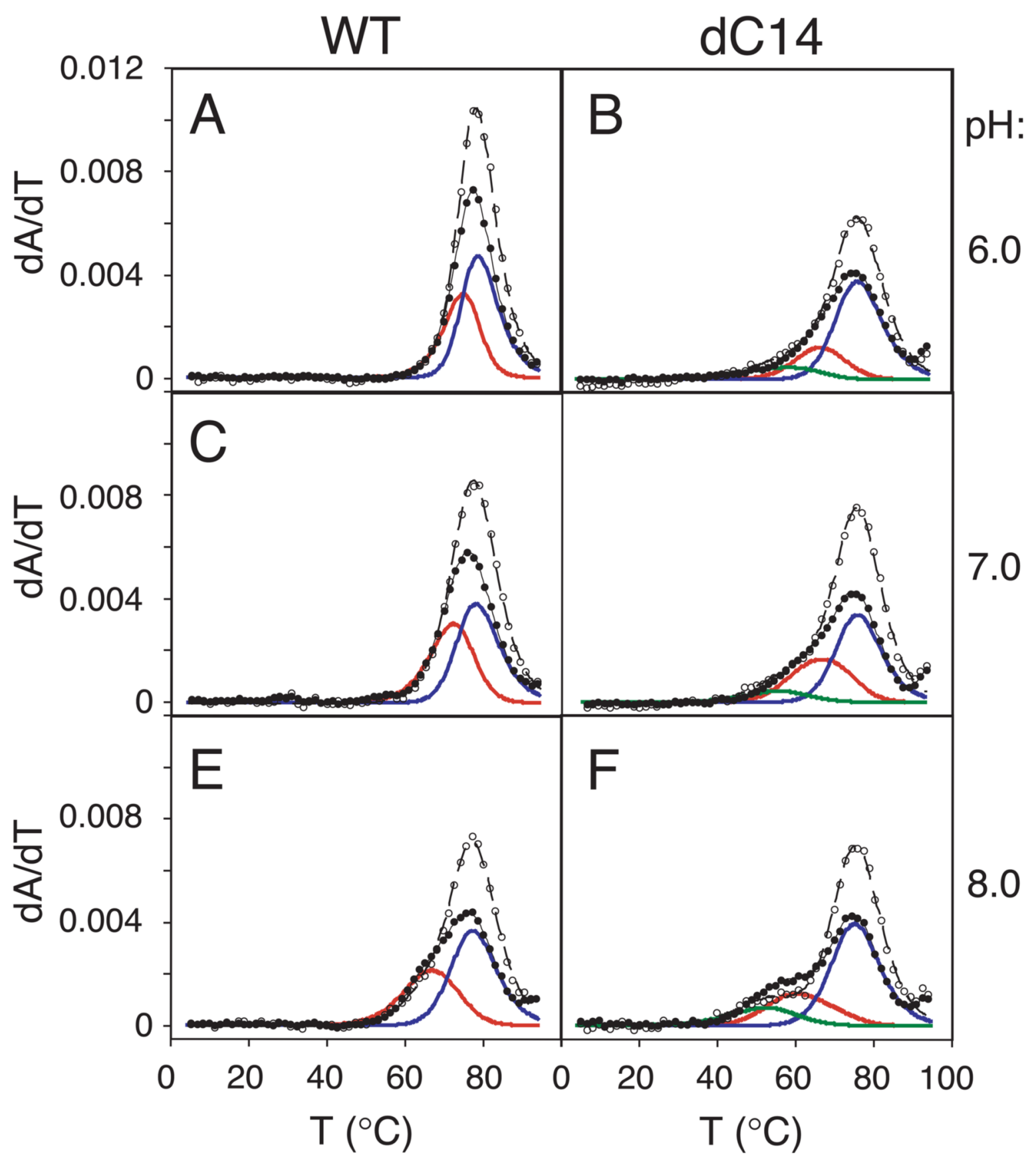

Figure 3.

Optically monitored thermal melting profiles acquired at $260(\bullet)$ and $280 \mathrm{~nm}(\mathrm{O})$ for the WT (panels A, C, E) and dC14 (B, D, F) ScYLV RNA pseudoknots at pH 6.0 (A, B), pH 7.0 (C, $\mathrm{D})$ and $\mathrm{pH} 8.0(\mathrm{E}, \mathrm{F})$. The smooth lines through the data represent the results of a nonlinear least squares simultaneous fit of the A260 and A280 melting profiles to either a two- (panels A, C, E) or three- (panels B, D, F) transition unfolding model. Best-fit component unfolding transitions at A260 are shown as continuous green, red and blue lines as defined by the two or three sequential unfolding transitions described by Schemes 1 (red, blue) and 2 (green, red, and blue solid lines), respectively. The resulting thermodynamic parameters derived from these 
fits are compiled in Tables S1-S2. Conditions: $10 \mathrm{mM}$ buffer salt, $0.5 \mathrm{M} \mathrm{KCl}$. Only every fifth data point is shown for clarity. 


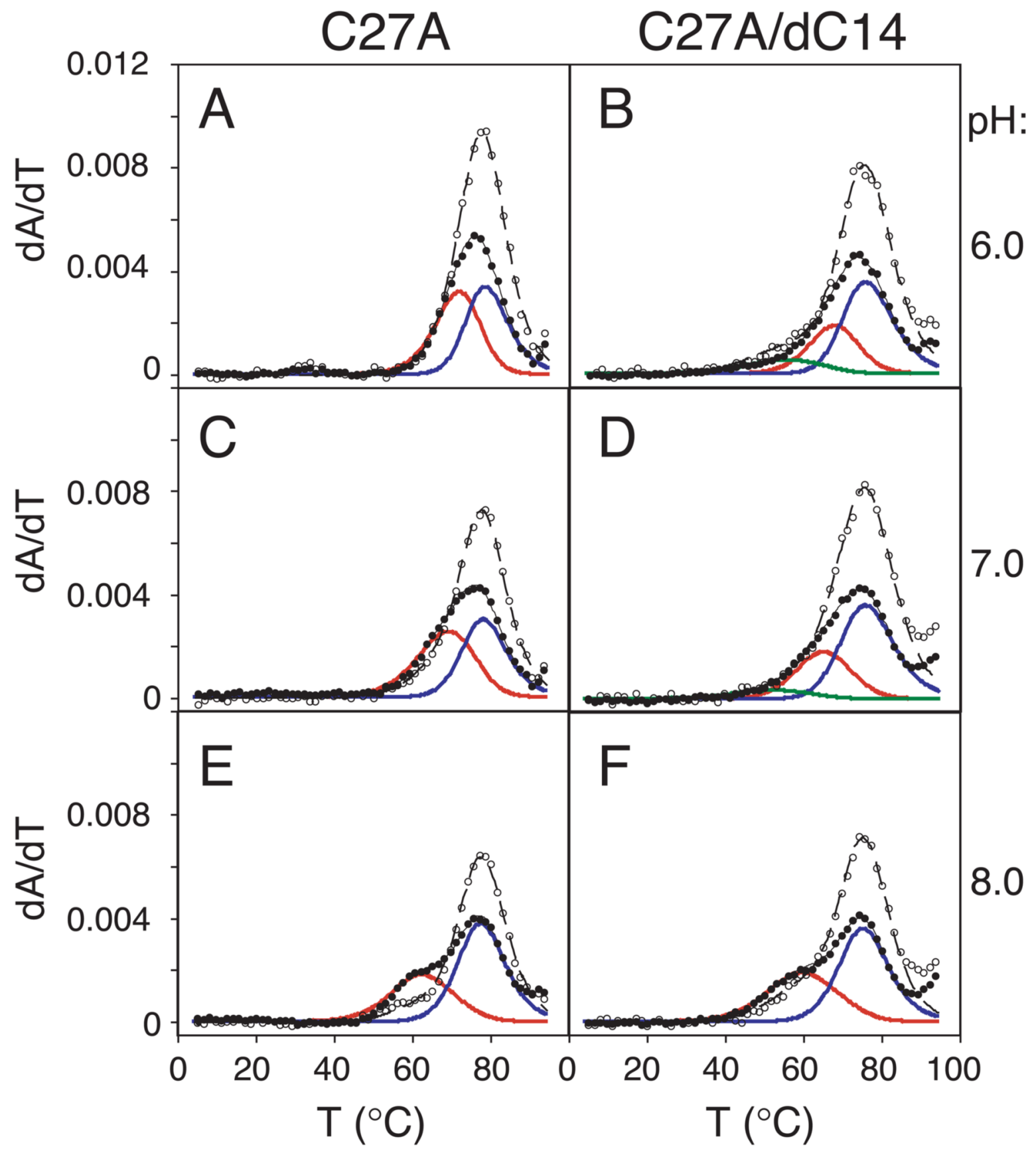

Figure 4.

Optically monitored thermal melting profiles acquired at $260(\bullet)$ and $280 \mathrm{~nm}(\mathrm{O})$ for the C27A (panels A, C, E) and dC14/C27A (B, D, F) ScYLV RNA pseudoknots at pH 6.0 (A, B), pH $7.0(\mathrm{C}, \mathrm{D})$ and $\mathrm{pH} 8.0(\mathrm{E}, \mathrm{F})$. The smooth lines drawn through the data represent the results of a nonlinear least squares simultaneous fit of the A260 and A280 melting profiles to either a two- (panels A, C, E) or three- (panels B, D, F) transition unfolding model. Best-fit component unfolding transitions at A260 are shown as the continuous green, red and blue solid lines as defined by the two or three sequential unfolding transitions described by Schemes 1 (red, blue) and 2 (green, red, and blue solid lines), respectively. The resulting thermodynamic 
parameters derived from these fits are compiled in Tables S3-S4. Conditions: $10 \mathrm{mM}$ buffer salt, $0.5 \mathrm{M} \mathrm{KCl}$. Only every fifth data point is shown for clarity. 


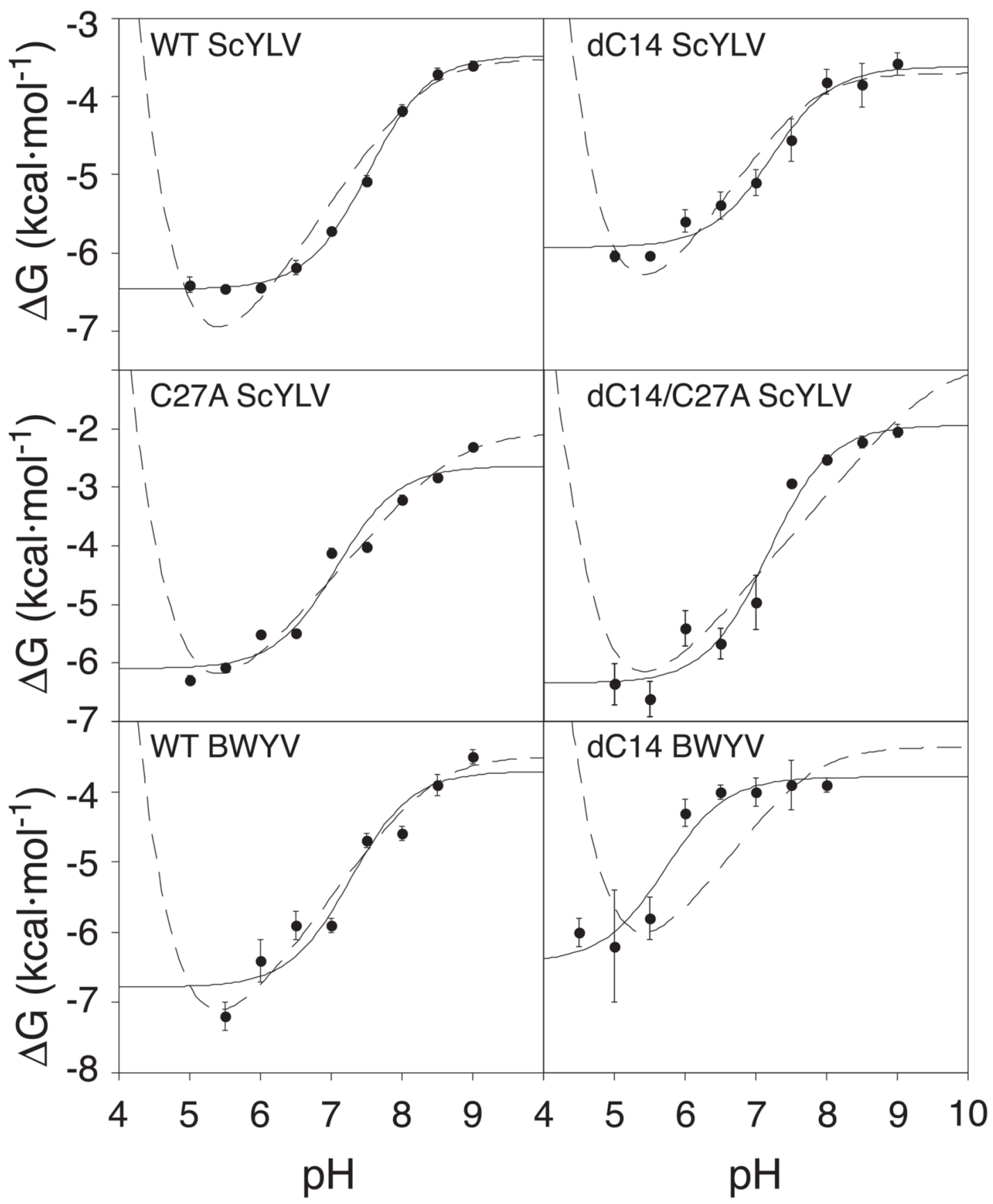

Figure 5.

Measured $\Delta G_{37}$ vs. pH for WT, dC14, C27A, dC14/C27A, BWYV and dC14 BWYV pseudoknots fit to two different models. $\Delta G=\Delta G_{1}$ for WT ScYLV RNA (see Table S1); $\Delta G=\Delta G_{1}+\Delta G_{2}$ for dC14 RNA (see Table S2); $\Delta G=\Delta G_{1}$ for C27A ScYLV RNA (see Table S3); $\Delta G=\Delta G_{1}+\Delta G_{2}$ for dC14/C27A RNA (between $\mathrm{pH} 5-7$ ) and $\Delta G=\Delta G_{2}$ (between $\mathrm{pH} 7.5-$ 9) (see Table $\mathrm{S} 4$ ). The continuous line (binding equation) through the experimental data represents a fit to a binding model, which ascribes the $\mathrm{pH}$-dependence of the unfolding to protonation of a single titratable group on the folded RNA (see text for details) (eq. 1). The dashed line (linkage equation) corresponds to a fit to the linkage model, which ascribes the $\mathrm{pH}$-dependence of the unfolding to a single ionizable group in the folded state, with multiple 
ionizable groups in the acid-induced unfolded state (eqs. 2-4). The parameter values and associated standard errors from these fits are compiled in Table 1. 


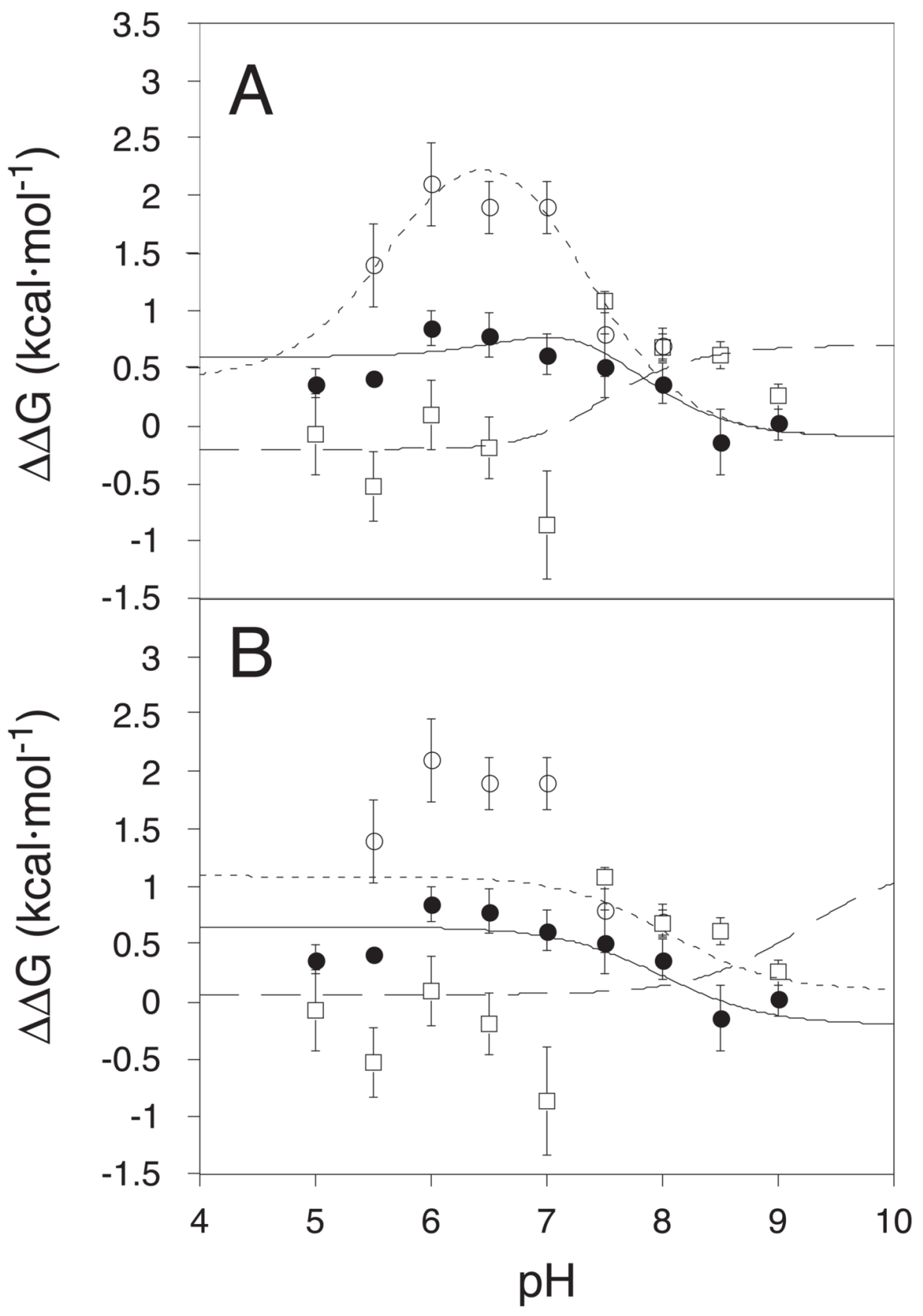

Figure 6.

Influence of $\mathrm{pH}$ on $\mathrm{dC} 14$ substitution mutants vs. corresponding WT counterpart. In both panels $\mathrm{A}$ and $\mathrm{B}$, filled circles represent experimentally determined values of $\Delta \Delta G_{37}=\Delta G_{37} \mathrm{dC14}$ $\Delta G_{37} \mathrm{WT}$, open squares, $\Delta \Delta G_{37}=\Delta G_{37} \mathrm{C} 27 \mathrm{~A} / \mathrm{dC1}{ }_{-}-\Delta G_{37}{ }^{\mathrm{C} 27 \mathrm{~A}}$, and open circles, $\Delta \Delta G_{37}=\Delta G_{37}$ BWYV/dC14 $-\Delta G_{37}{ }^{\mathrm{BWYV}}$ (20) from the data shown in Fig. 5. (A) Simulated curves derived from the parameters from the binding equation fits (eq. 1 and Table 1) to the $\mathrm{pH}$ dependence. Solid line, $\Delta \Delta G_{37}(p H)=\Delta G_{37} \mathrm{dC14}(p H)-\Delta G_{37} \mathrm{WT}^{\mathrm{W}}(p H)$; dashed line, $\Delta \Delta G_{37}(p H)=$ $\Delta G_{37}{ }^{\mathrm{C} 27 \mathrm{~A} / \mathrm{dC} 14}(p H)-\Delta G_{37}{ }^{\mathrm{C} 27 \mathrm{~A}}(p H)$ dotted line, $\Delta \Delta G_{37}(p H)=\Delta G_{37} \mathrm{BWYV} / \mathrm{dC} 14(p H)-$ $\Delta G_{37}{ }^{\mathrm{BWYV}}(p H)$. (B) Simulated curves derived from the parameters obtained from the linkage equation fits to the $\mathrm{pH}$-dependence (eqs. 2-4). Solid line, 
$\Delta \Delta G_{f}(p H)=\Delta G_{f}^{\mathrm{dCl} 14}(p H)-\Delta G_{f}^{\mathrm{WT}}(p H) ;$ dashed line,

$\Delta \Delta G_{f}(p H)=\Delta G_{f}^{\mathrm{C} 27 \mathrm{~A} / \mathrm{dC14}}(p H)-\Delta G_{f}^{\mathrm{C} 27 \mathrm{~A}}(p H) ;$ dotted line,

$\Delta \Delta G_{f}(p H)=\Delta G_{f}{ }^{\mathrm{BWYV} / \mathrm{dCl} 14}(p H)-\Delta G_{f}^{\mathrm{BWYV}}(p H)$. 


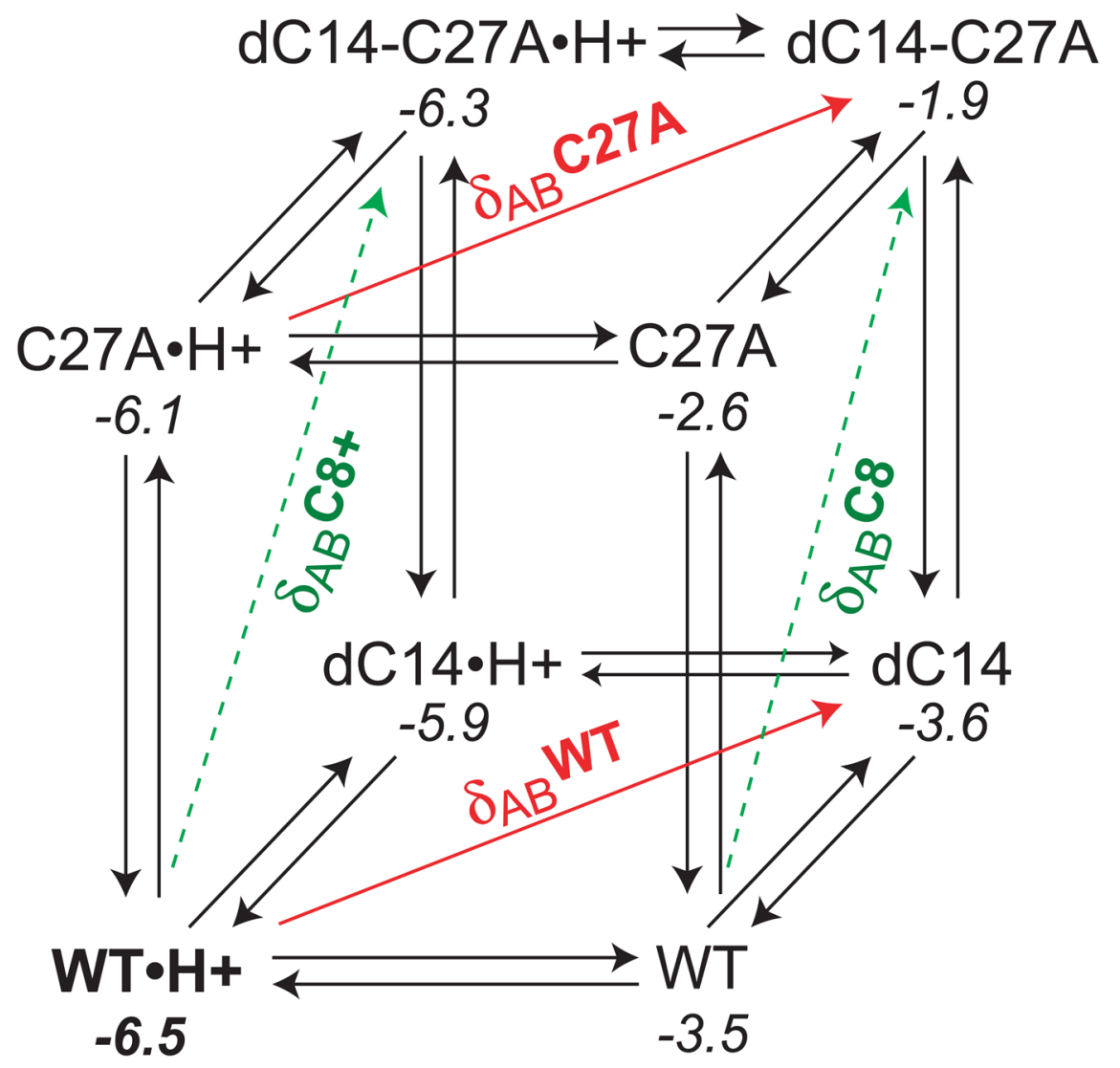

Figure 7.

Thermodynamic cube that encompasses all linkage relationships between the various ScYLV RNAs investigated in this work. The global reference state is the wild-type ScYLV RNA at low $\mathrm{pH}, \mathrm{WT} \cdot \mathrm{H}+$. The numbers in italics below each RNA represent the folding free energies $\left(\Delta G_{37}\right)$ derived from the binding equation (eq 1) fits (given in Table 1). Each $\delta_{\mathrm{AB}} i$ is described in the text, with all six pairwise $\delta_{\mathrm{AB}}{ }^{i}$ compiled in Table 2. 

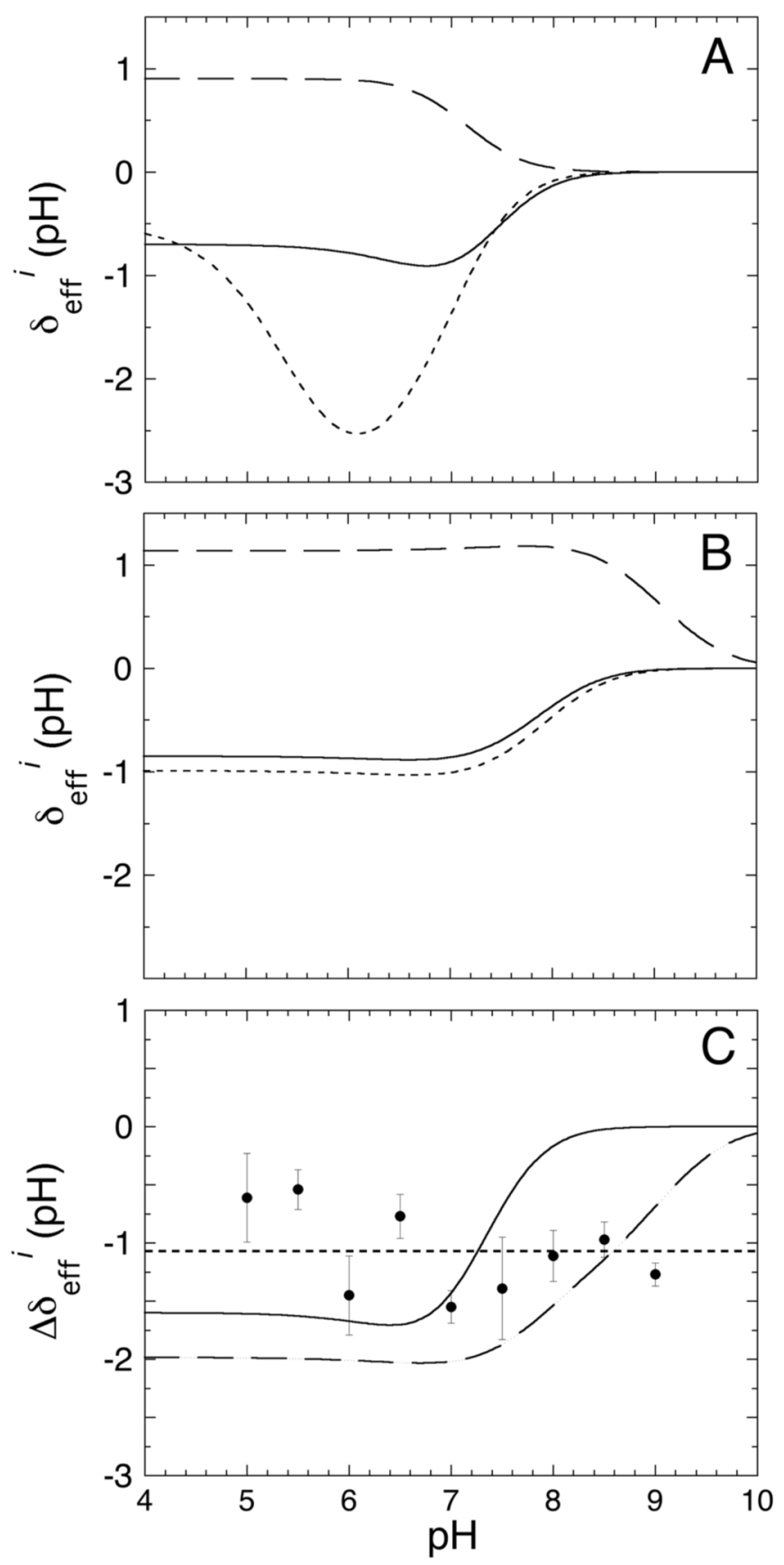

Figure 8.

Effective coupling free energies, $\delta_{\mathrm{AB}}$,eff, as a function of $\mathrm{pH}$. (A) Simulated curves derived from eq. 14 are shown for the WT ScYLV (solid line), C27A ScYLV (dashed line), and BWYV (dotted line) RNAs derived from parameters obtained from the binding equation fits (Table 1) to eqs. 10-13. (B) Simulated curves derived from eq. 14 for parameters derived from the linkage equation fits (Table 1). (C) Simulated curves drawn for $\Delta \delta_{\mathrm{AB}}{ }^{\text {eff }}=\delta_{\mathrm{AB}}{ }^{\mathrm{WT}, \text { eff }}-\delta_{\mathrm{AB}}{ }^{\mathrm{C} 27 \mathrm{~A}, e f f}$ derived for the binding equation fits (solid line; equals the solid line-dashed line from panel A) and linkage equation fits (dashed line; equals the solid line-dashed line in panel B), compared to global $\Delta \Delta G_{37}$ measured previously (16). 


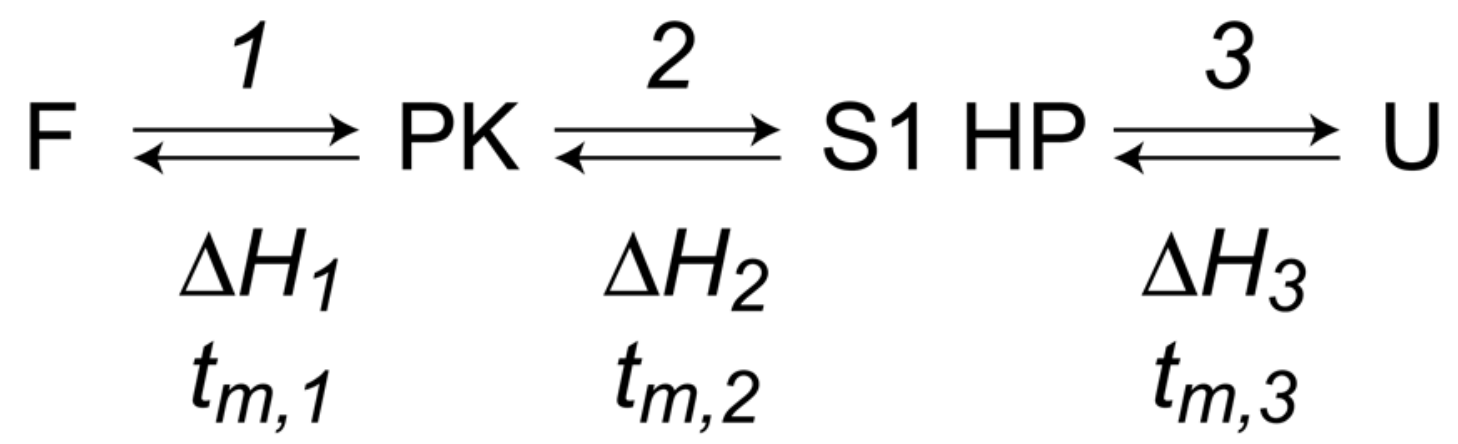

Scheme 1. 


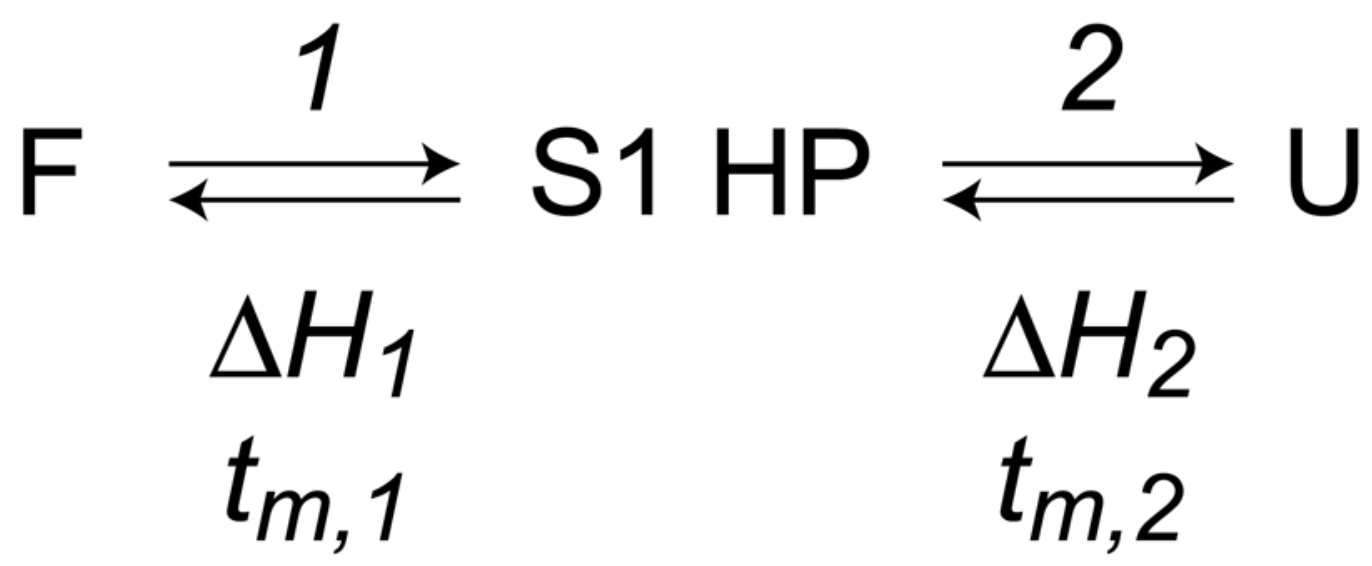

Scheme 2. 


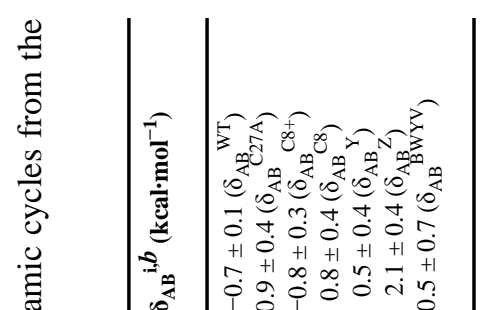

